\title{
Editorial
}

\section{A Revista de Informática Teórica e Aplicada e as Tecnologias de Informação}

\author{
José Palazzo M. de Oliveira e Luis C. Lamb
}

\begin{abstract}
Resumo: Este artigo apresenta uma breve visão da história da Revista em relação às Tecnologias da Informação, descreve as ações que estão sendo tomadas para incrementar sua participação na comunidade acadêmica de Ciência da Computação utilizando-se das possibilidades da Web, e descreve as próximas funcionalidades que serão desenvolvidas.
\end{abstract}

Palavras-chave: RITA, Bibliotecas Digitais, Tecnologia da Informação.

\section{Introdução}

A Revista de Informática Teórica e Aplicada - RITA - está sendo publicada, continuamente, desde 1989. Nestes anos foram impressos 25 números. O objetivo inicial foi atingir o público acadêmico de Ciência da Computação do Brasil.

Em paralelo foi iniciada a publicação, pioneira no Brasil, de uma Edição Eletrônica. Esta edição visava à difusão mais rápida de notícias, chamadas de congressos e descrições de grupos de pesquisa. Utilizando a tecnologia, recentemente disponibilizada pela Bitnet, de listas. Infelizmente, apenas dois números da edição eletrônica foram preservados, e estes números podem ser visualizados a partir da página Web da revista. Esta iniciativa foi descontinuada quando da expansão da Rede Nacional de Pesquisa que tornou desnecessária a centralização de informações.

$\mathrm{Na}$ área da pesquisa científica a importância de se ter acesso aos resultados de uma pesquisa, logo que ela é realizada, é muito maior do que em áreas mais estáveis. Quando um pesquisador publica o resultado de experimentos de seu trabalho em uma revista científica ou em um congresso, outros pesquisadores podem ter acesso a esses dados e utilizá-los como material bibliográfico para estudo ou realização de novas pesquisas. Tradicionalmente o acesso a essas publicações era limitado e dependia da disponibilização desses artigos em 
bibliotecas. A disponibilização ampla de acesso à Internet criou a percepção que artigos publicados na Web têm maior penetração e influência [1]. Em consequiência passamos a disponibilizar a versão integral dos artigos publicados na versão impressa em formato PDF a partir do site da Revista. Esta ação produziu resultados imediatos que podem ser avaliados por uma busca no serviço Scholar da Google (http://scholar.google.com). Em decorrência, apesar do pouco tempo desta oferta, uma busca realizada no site encontrou 60 entradas para artigos publicados na Revista com cerca de 53 citações.

Neste ano foi realizada a inclusão da Revista de Informática Teórica e Aplicada no sistema DBLP (http://www.informatik.uni-trier.de/ ley/db/journals/rita/index.html) o que aumentou muito a visibilidade da mesma.

Finalmente, o sistema de submissão e avaliação dos artigos foi transferido para a plataforma de submissões eletrônicas da SBC (EDAS) como contrapartida do financiamento recebido da FAPERGS pelo Instituto de Informática. Esta decisão aumentou significativamente o número de submissões sendo que nos últimos seis meses recebemos 10 submissões do exterior e 31 submissões nacionais.

Este breve resumo da utilização das Tecnologias da Informação mostra o pioneirismo e a atualização da Revista. A seguir descreveremos as bases do desenvolvimento de uma Biblioteca Digital para disponibilizar o conteúdo da RITA como um Web Service.

\section{Biblioteca Digital}

Uma tecnologia que oferece a possibilidade da troca de conhecimento através da Internet e que tem crescido bastante desde seu surgimento é a Open Archives Initiative (OAI) [2]. O OAI provê uma forma padrão para disponibilização de documentos na Internet, e também, para coleta de informações desses documentos de forma a permitir consultas.

A tecnologia OAI fornece um framework que facilita a publicação de documentos e de informações sobre esses documentos (metadados) na Internet. OAI permite reunir informações sobre documentos distribuídos em diversas partes da rede, através de uma colheita de metadados.

A arquitetura OAI possui dois componentes principais: Data Provider e Service Provider. O Data Provider é um repositório que possui metadados sobre os documentos e permite a realização de consultas através do protocolo OAI-PMH (Open Archives Initiative Protocol for Metadata Harvesting) [3]. O Service Provider realiza uma coleta de metadados em diversos Data Providers, através do protocolo OAI-PMH e também oferece diferentes serviços aos usuários, como por exemplo, busca e citação. A arquitetura OAI pode ser vista na figura 1. 
A Revista de Informátcia Teórica e Aplicada ao dis ponibilizar os artigos em uma biblioteca digital, que utiliza a tecnologia OAI, oferece um serviço Data Provider. Assim, um pesquisador poderá encontrar essa publicação realizando uma consulta em um Service Provider. O Service Provider realiza uma coleta pr metadados em um ou mais Data Providers e disponibiliza esses dados para consulta. Esses metadados recuperados do Service Provider estão no formato Dubin Core [4]. Em uma primeira implementação os artigos serão acessíveis pelo serviço BDBComp [5]. Todos os artigos publicados na RITA serão disponibilizados publicamente através de um Service Provider assim como os conteúdos em arquivos PDF.

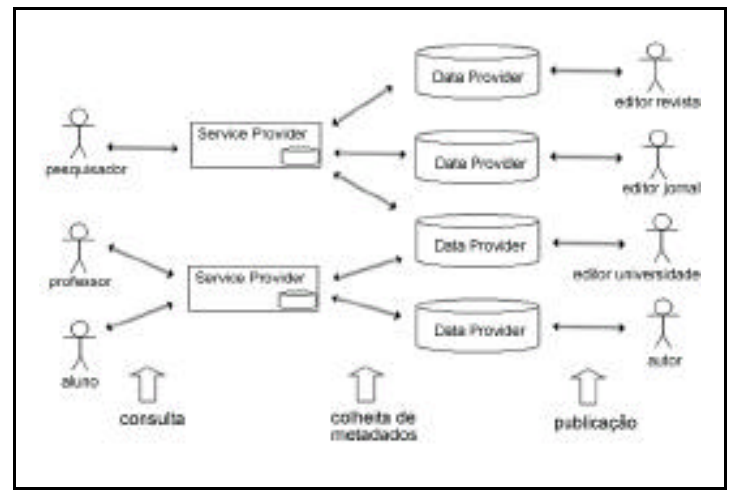

Figura 1. Arquitetura OAI

\section{Conclusões}

O caminho trilhado nestes últimos 15 anos utilizou, sempre, as tecnologias mais atuais disponíveis. Atualmente estamos desenvolvendo a infra-estrutura necessária para a inserção da Revista no pool mundial de bibliotecas digitais.

O objetivo desta publicação sempre foi o de oferecer um veículo ibero latinoamericano de alta qualidade. Gradualmente, esperamos que as submissões de regiões mais amplas consolidem-se e que a revista projete-se ainda mais na comunidade científica internacional de Ciência da Computação.

\section{Bibliografia}

[1] Online or Invisible? Steve Lawrence; Nature, Volume 411, Number 6837, p. 521, 2001. Também disponível em http://citeseer.ist.psu.edu/online-nature01/

[2] Open Archives Initiative. On-line. http://www.openarchives.org/ 
[3] Open Archives Initiative Protocol for Metadata Harvesting. On-line. http://www.openarchives.org/OAI/openarchivesprotocol.html

[4] Dublin Core Metadata Initiative. On-line. http://dublincore.org

[5] Alberto H. F. Laender, Marcos André Gonçalves, Pablo A. Roberto. BDBComp: building a digital library for the Brazilian computer science community. Proceedings of the 4th ACM/IEEE-CS joint conference on Digital libraries 2004, Tuscon, AZ, USA, June 07 - 11, 2004, pp. 23 - 24 